\title{
Better healthcare must mean better for patients and carers
}

\author{
(). (1) $\Theta$ OPEN ACCESS \\ Their perspectives are essential to all successful healthcare improvement
}

Anya de longh patient editor ${ }^{1}$, Sibylle Erdmann chair of parent group ${ }^{2}$

${ }^{1}$ The BMJ, London, UK; ' 2 London Neonatal Network, London, UK

Quality improvement in healthcare is a team effort ${ }^{1}$ and most effective when it includes people using services and their carers, families, and advocates. These people bring direct expertise in matters of health from their personal experience of illness as well as skills from lives beyond the healthcare system.

Some aspects of healthcare undeniably need to be improved, but the quality deficit needs to be clearly described from every angle. We can do things better or we can do better things, but both usually mean acting differently. Patients, carers, and their advocates are a vital source of different perspectives in healthcare.

The invitation to patients to get involved needs to be both timely and respectful. In a board meeting discussing quality indicators, for example, it is demeaning to refer to the participating parent as "mummy." Looking at someone through this lens blinds us to the other life experiences they may have had in their professional career. We need to respectfully acknowledge all the attributes, qualities, and skills that people bring to the table, whether gained through their patient experiences or other personal or career experiences.

In healthcare improvement we are asking patients to play a range of roles in an invisible script, from telling their story, to being representative of a broader group, to partners in coproduction. It's not always clear which of these roles patients are asked to play. ${ }^{2}$ Patients can find themselves stuck in limbo between two expected roles or trying to second guess what is required. In this situation, doing better means improving the relevance and practical impact of every contribution.

The level of patient involvement will differ according to the requirements of projects and the preferences of individuals. At all levels, quality of input trumps quantity. Patients and carers already provide solicited and unsolicited insights into their experiences of services. "Feedback fatigue" can set in if the purpose of further feedback requests isn't clear. New information isn't always better information, as criticism of the NHS friends and family test has recently explored. ${ }^{3}$

Paying attention to the quality of language is the foundation for successful dialogue and everyday collaboration. Many patients and carers can describe the pain caused by a single word they encountered while being treated. Especially with new words and labels, it is important that we are respectful towards their owners. For instance, only people with experience of dementia can verify which services are indeed dementia friendly.

In recent years, we have seen a qualitative expansion of the boundaries of the traditional patient-doctor relationship. ${ }^{4}$ Patient advocates are becoming more confident when exchanging knowledge with clinicians and researchers about medical conditions, bringing in their knowledge from outside the medical arena. But we still have some way to go before all clinicians welcome every patient contribution, either during consultations or in discussing service improvements. One example of better healthcare might be that we no longer hear patients, carers, or healthcare professionals say, "I was too afraid to ask or say..." Beyond these personal encounters, patients also have a key role in organisational change to improve healthcare. The delicate balance of sometimes competing drivers such as speed, volume, integration, and specialisation all directly affect people who use health services, so their perspectives need to inform this bigger picture too. Models already exist to involve people, their carers, families, and advocates in all aspects of organisational improvement. ${ }^{5}$ The common thread across these is timeliness-involvement early is always better.

Any quality improvement effort can produce unintended collateral damage for patients if the "improvement" is one dimensional. The flaws of improvement initiatives will be invisible until users miss the refuge of a kitchen with a toaster in a children's ward or the comfort of a biscuit during regular intravenous treatments. ${ }^{6}$ Proper collaboration early in the change 
process can give insight into what these unintended consequences might be and how to avoid them. Collaboration works both ways. With a deeper connection and appreciation of the rationale for decisions and the constraints that we all operate under (organisational, clinical, personal) we can learn together-and that is always better.

For people using services, better healthcare is personal, as we juggle self managing an illness with the practicalities of daily life. Often, better actually means choosing the least worst of a limited menu of options. To judge what is better from a patients' point of view, we must remember that the starting point is a profoundly disruptive life event. Living through illness gives individuals a unique insight of enormous value to quality improvement efforts. These efforts must recognise the qualitative nature of patient experience and give it equal priority with the experience of healthcare professionals providing clinical services. The two elements fit hand in glove, even if our language and systems don’t always reflect it.

Competing interests: We have read and understood BMJ policy on declaration of interests and declare $S E$ is a founding member of $Q$, a healthcare improvement initiative led by the Health Foundation and supported by NHS Improvement. She is also a member of The BMSs patient panel.
Provenance and peer review: Commissioned; not externally peer reviewed. This article is one of a series commissioned by The BMJ based on ideas generated by a joint editorial group with members from the Health Foundation and The BMJ, including a patient/carer. The $B M J$ retained full editorial control over external peer review, editing, and publication. Open access fees and The BMJ's quality improvement editor post are funded by the Health Foundation.

1 Miller R, Miller R, Gardner T, Warburton W. Briefing. Partnerships for improvement: ingredients for success. Health Foundation, 2017. https://health.org.uk/sites/health/files/ PartnershipsForlmprovement.pdf

2 Liabo K, Boddy K, Burchmore H, Cockcroft E, Britten N. Clarifying the roles of patients in research. BMJ 2018;361:k1463. https://www.bmj.com/content/361/bmj.k1463. 10.1136/bmj.k1463 29636343

3 Robert G, Cornwell J, Black N. Friends and family test should no longer be mandatory. BMJ 2018;360:k367. 10.1136/bmj.k367 29378693

4 Riggare S. E-patients hold key to the future of healthcare. BMJ 2018;360:k846. https:// www.bmj.com/content/360/bmj.k846. 10.1136/bmj.k846 29483151

5 NHS England. Patient participation resources. https://www.england.nhs.uk/participation/ resources/

6 Giles C. Jeremy Hunt stole my biscuits. BMJ Opinion, 31 Oct 2017. http://blogs.bmj.com/ bmj/2017/10/31/ceinwen-giles-jeremy-hunt-stole-my-biscuits/

Published by the BMJ Publishing Group Limited. For permission to use (where not already granted under a licence) please go to http://group.bmj.com/group/rights-licensing/ permissions This is an Open Access article distributed in accordance with the Creative Commons Attribution Non Commercial (CC BY-NC 4.0) license, which permits others to distribute, remix, adapt, build upon this work non-commercially, and license their derivative works on different terms, provided the original work is properly cited and the use is non-commercial. See: http://creativecommons.org/licenses/by-nc/4.0/. 